\title{
Differential morphophysiological characteristics of erythrocyte precursors and mature erythroid cells in early postnatal ontogenesis of birds
}

\author{
E. A. Kolesnik, M. A. Derkho, V. K. Strizhikov, S. V. Strizhikova, F. G. Gizatullina, T. A. Ponomaryova \\ South Ural State Agrarian University \\ Russia
}

\begin{abstract}
In accordance with the recommendations of The International Council for Standardization in Haematology (ICSH, https://icsh.org/), this article describes the morphophysiological characteristics of the precursors and mature erythroid cells in the early period of postnatal development of birds (Gallus gallus L.) including calculation of the surface area of these cells $(S$, $\mu \mathrm{m}^{2}, \mathrm{X} \pm$ SEM).

Depending on cell shape, cytoplasm color, and chromatin organization in nucleus, the following types are distinguished: basophilic erythroblasts $\left(69.60 \pm 4.01 \mu \mathrm{m}^{2}\right.$, $\mathrm{p} \leq \mathbf{0 . 0 5})$, polychromatophilic erythroblasts $(65.42 \pm 2.49$ $\left.\mu \mathrm{m}^{2}, \quad \mathrm{p} \leq 0.05\right)$, and oxyphilic erythroblasts $(71.10 \pm 4.43$ $\left.\mu \mathrm{m}_{2}\right)$. Formation of cell pool is characteristic for erythropoiesis in birds due to mitotic proliferation of basophilic erythroblasts. There are often proerythroblasts and polychromatophilic erythroblasts. The nucleus of a polychromatophilic proerythroblast contains a large number of histone proteins; therefore, it has an intensely basophilic color with a pronounced oxyphilic hue (proteinrelated oxyphilia). The accumulation of hemoglobin in the protoplasm of these cells contributes to the gradual transition of the basophilic staining of cytoplasm to the oxyphilic one which is typical for mature red blood cells $\left(73.95 \pm 2.10 \mu \mathrm{m}^{2}, p \leq 0.05\right)$. Cell shape and the structure of erythroblast nucleus approaches to these of mature red blood cells.
\end{abstract}

Keywords: blood morphology, proerythroblasts, erythroblasts, normocytes, red blood cells, erythropoiesis, hemocytopoiesis, mitosis, chickens.

\section{INTRODUCTION}

$\mathrm{R}^{\mathrm{m}}$ ED blood cells carefully reflect the physical condition of an organism. Morphopathological changes in red blood cells are both separate nosological criteria for a whole spectrum of anemias, and symptomatic complexes of pathologies of endocrine glands, including clinical characteristic of liver [1]-[10] as well as adaptation processes [11], [12].

In this case, the most important aspect of physician's perception of very delicate, melting line between normal and pathological values in medical history is a correct understanding and ability to diagnose and differentiate the morphophysiological features of the structure of blood cells in the normal physiological state of their growth and development [13]-[16]. For example, in studies [17] it was established that the functional state of mitochondria of erythrocytes of birds is associated with the processes of aging of the body and a change in the speed and direction of redox reactions. At the same time, bird erythrocyte mitochondria are capable of producing mitochondrial superoxide.

In addition, postembryonic hemopoiesis in birds (Aves) differs significantly from this in mammals (Mammalia); in birds, there is no definite division of hematopoiesis into myeloid and lymphoid systems [18]-[20].

Hemocytopoiesis in adult birds is morphologically and functionally to a great extent similar to embryonic hematopoiesis [21]-[23].

The presence of proerythroblasts and erythroblasts in peripheral blood is a characteristic feature of the postnatal development of birds. In the blood of chickens, by the first day after hatching, erythroblasts amount to $14 \%$ of the total number of formed elements.

Circulation of erythroblasts in the blood of chickens continues until they reach the age of three months. Maximal erythropoiesis in chickens occurs at the end of the first week what is comparable and due to the onset of critical age periods in the development of chickens.

We would like to emphasize the importance of gradation in the names of erythrocyte precursor cells: primary blast (from Greek "blastos" - a germ), and subsequent, actually cell ones (from Greek "cytos" - a cell. This is associated with the ability of blast blood cells to actively proliferate in the body of birds by mitosis. Due to the fact that blast blood cells are actively proliferating, that is, propagating through mitosis. In addition, the structure of nucleus, protoplasm and cell shape of "-blasts" and "-cytes" are significantly different. Blast cells (ending with "- blasts") are round-shaped cells, with a nucleus, often having a chromatin pattern of any stage of mitosis while actual cell forms of erythrocyte precursors (ending with "-cytes") more often have the shape and nucleus structure similar to these of mature red blood cells [24].

Of the common prescriptions for staining blood smears, the protocol of histological method proposed by A. Pappenheim allows the most qualitative fixation and identification of the color of formed elements, and consequently, reliable differential diagnostics of blood cells. However, only a few 
publications provide high-quality colored micrographs of avian blood cells obtained by light optical microscopy.

Normal picture of the peripheral blood of chickens includes proerythroblasts in different stages of mitosis. This fact should be considered in the course of clinical diagnostics in order to avoid errors in distinguishing physiological and pathophysiological conditions.

Moreover, microphotographs of these proliferating erythroblasts are very rare in specialized literature. There are few colored micrographs of mitotic polychromatophilic erythroblasts of a dog (Canis lupus familiaris) ("mitotic polychromatophilic rubricyte". In reseach [25] showed a colored micrograph of mitotic erythroblast from the peripheral blood of a bird, greater rhea (Rhea americana), in late anaphase. The publication presents photographs of mitotic figures of erythroblasts (rubricites) from the peripheral blood of clinically healthy emu birds (Dromaius novaehollandiae).

In the same time colored micrographs of mitotic proerythroblasts of chickens Gallus gallus L. are shown only in several works.

In addition, the literature on the general morphology of animal erythrocytes is very fragmented. According to [26], the size and shape of cells is associated with the age of birds, morphological features - with the duration of circulation in the bloodstream and resistance to oxidative stress [27], the tendency of red cells to transform shape, both by shortening the life time in the bloodstream, and degeneration - with the ecological state of the environment [28]. In addition, the species of birds, their lifestyle and environmental conditions also affect the morphological and cytochemical characteristics of red blood cells. According to the morphological features of red blood cells, as well as the appearance in the bloodstream of transformed and degeneratively altered cells indicate the appearance of pathological changes in the animal body.

An analysis of the literature data on the problem under study revealed its little knowledge and the lack of unified approaches to the classification of erythroid cells. This actualizes the research topic, allowing us to expand our understanding of the change in the erythroid pool in the peripheral blood of broiler birds during the early stages of postnatal ontogenesis in an industrial environment.

Thus, the aim of this work was to find and to describe differential morphophysiological markers of erythroid cells of birds in the early period of ontogenesis after birth based on the morphofunctional analysis of colored micrographs of peripheral blood cells of chickens Gallus gallus (L.).

\section{MATERIALS AND METHODS}

The studies were carried out as part of a comprehensive program for studying the physiological adaptations of homeostasis of broiler chickens of neonatal ontogenesis grown under standardized industrial technologies (Hubbard ISA Guide, URL: http://hubbardbreeders.com/).

The research subject, based on the goal of the work, included:

1. analysis of literature on the desired issues of published information on the morphophysiology of red blood cells and their ontogenetic precursors in the blood of birds;

2. identification and interpretation of differential morphophysiological parameters of erythroid pool cells of an early period of ontogenesis after birth.

The study was conducted in accordance with the principles of humanity set forth in the directives of the European Parliament of the Council of the European Union for the protection of animals used for scientific purposes: DIRECTIVE 2010/63 / EU OF THE EUROPEAN PARLIAMENT AND OF THE COUNCIL of 22 September 2010 on the protection of animals used for scientific purposes (Directive 2010/63 / EU: URL: https://eur-lex.europa.eu/legalcontent/EN/TXT/PDF/?uri=CELEX:32010L0063).

The experimental part of the work was performed at Chebarkulskaya Poultry LLC (Chebarkulsky District, Chelyabinsk Region, Russian Federation).

Selected subject of study: the highly productive, widely spread avian cross meat breeding of Hubbard ISA F15 broiler chickens (selection: Institut de Sélection Animale (ISA), the ISA Group merged with Merck \& Co., forming Hubbard Inc., USA) was grown by an industrial herd in broiler workshop (content in cell batteries - brooders) - the general population of the studied birds.

From which, according to the principles of random sampling and balanced groups, four (4) experimental groups were formed $(n=10)$ depending on age:

Group I - 1-day old chicks;

II - 7-day-old chickens;

III - 23-day broilers;

IV - 42-day-old chickens.

The experimental groups corresponded to the days of postnatal ontogenesis: P1, P7, P23, P42 (Postnatalis) in the neonatal periodization of growth and development.

The periodization of neonatal ontogenesis of broiler chickens by bird age (in days) has the following characteristic of the physiological period of early postnatal ontogenesis.

The age of the first day of broiler chickens is characterized by the completion of the expenditure of nutrients in the yolk sac, unstable homeotherm, the beginning of adaptation to neonatal growth and development.

The seven-day age of a broiler bird is characterized by the beginning of the formation of full-fledged homeothermism, a complete transition to exogenous nutritional dependence, there is a restructuring to assimilate the feed of the external environment: the functional activity of the digestive organs and glands of internal secretion develops. The beginning of the formation of postnatal feather cover. The immune system is actively developing.

The age of twenty-three days in broiler chickens is characterized by intensive growth of the bird, chickens become highly mobile, consume more feed. By the end of the second decade, juvenile (age) molting begins.

Broiler chickens at the age of forty-two days are distinguished by the most active period of constitutional skeletal muscle formation.

The experimental groups of chickens Gallus gallus L. according to Anamnesis vitae clinically (status praesens) 
corresponded: fusce sanitas status to the status of healthy animals.

Feeding and keeping the experimental bird was carried out in accordance with nutritional and zoohygienic standards in accordance with the recommendations (Hubbard ISA Manual, URL: http://hubbardbreeders.com/).

The smears of the peripheral blood of the chicks of the experimental groups were stained according to the protocol (histological scheme) of Pappenheim (A. Pappenheim).

Pappenheim blood smear staining is a combined histochemical reaction scheme that includes two steps. At the first stage, fixation is performed (with methanol, as a part of the dye) and simultaneously stained with methylene blue and eosin according to the May - Grunwald scheme (dye). In the second, final stage. The smears are stained with a buffered dye according to the Romanovsky scheme, including azure and azure oxidation products, eosin. After that, the smears are washed with tap water and then rinsed with distilled water.

The Pappenheim cytochemical protocol, thanks to the combined multi-pigment scheme, allows the most qualitative visualization of the cell structures in the studied blood smears.

In order to preserve the prepared smears for repeated work, the dried blood smears, after a two-minute ( $2 \mathrm{~min}$.) Exposure in xylene (Clean for analysis), were enclosed in the original Canadian balsamum (Canadian balsamum) for histological studies (PANREAC, Spain).

Microphotographs were performed on a large biological microscope (MBB - 1 A, LOMO, Russia) with a 5 megapixel micrographic ocular video camera (Full HD High resoltuion "HAYEAR" CMOS 5.0 Megapixel microscope video camera, China), with imaging, in ToupView (ToupTek Photonics, PRC, URL: http://www.touptek.com/). With a built-in a lightemitting diode (LED) system, for illumination of micropreparations with a white spectrum, according to the Köhler principle (A. Köhler).

The illumination system in a microscope according to the Koehler principle is the best, since, in this case, the greatest uniformity of illumination of the field of view in the microscope is achieved. Application of the Köhler principle in illumination of micropreparations implements the correct geometry of the light-optical system of the microscope, therefore, provides adequate color reproduction when performing microphotographs and as a result allows you to get pictures with the least possible distortion.

For the most correct color and light transmission in images of blood cells, the so-called white balance is very important in the lighting system of the microscope and the image of the field of view on the monitor (display); In order to obtain the optimal white balance, we used a special compensation and corrective light yellow filter (LOMO, Russia) placed in the frame holder of the microscope condenser.

For the most high-quality image of blood cells, a 90-fold apochromatic oil immersion lens with an aperture of 1.3 was used (LOMO, Russia).

The apochromatic microscopic 90 -x oil immersion lens with an aperture of 1.3 (LOMO, Russia) has an optical design with corrected spherical aberration and chromatic aberration.
In contrast to the widespread achromatic optical systems of micro-lenses, in which the focal length coincides for two different wavelengths of visible light, for apochromatic microscopic lenses, the focal length is equal at three points in the spectrum, and the secondary light spectrum is corrected from spherical and chromatic aberrations.

The use of this apochromatic microscopic lens allows you to get clear microphotographs without optical distortion, and accordingly conducts a qualitative morphophysiological analysis of blood cells studied in smears with minimal subjective errors.

Calibration of the video camera was carried out on the scale of a micrometer object for transmitted light with a division value of $0.01 \mathrm{~mm}$ ("OMP" GOST 7513 - 55 "LOMO", Russia) in the "ToupView" program.

In the ToupView program, the scale of the images was determined, and a scale ruler with a division price of $10 \mu \mathrm{m}$, respectively, was placed on microphotographs.

In the program "PhotoM 1.21" (Russia) (http://tlambda.chat.ru/download.html) the area of erythrocyte precursors and mature erythroid cells was determined: S (cell area), $\mu \mathrm{m}^{2}$.

All digital data of the measured and analyzed values of the studied parameters of the subject of study are represented by the arithmetic mean $(\mathrm{X})$ and standard error of the mean: Standard Error Mean ( \pm SEM).

The statistical hypothesis about the normality of the distribution in the sample of the studied parameters was tested using the STATISTICA program, version 8.0, "StatSoft, Inc.", USA, using the Kolmogorov - Smirnov test for normality and the Shapiro - Wilk criterion (Shapiro - Wilk's W test), as well as the normal probability plot (Normal probability plot: "Normal P-Plot"). As a result of this, the hypothesis of the normal distribution of the considered values of the parameters of the subject of study was confirmed.

The degree and significance of differences for the obtained results was evaluated using the parametric $T$ - test (single sample) in the STATISTICA 8.0 program (StatSoft, Inc., USA).

The critical level of significance of the difference in values was taken as $\mathrm{p} \leq 0.05$.

\section{RESULTS}

As a result of the study, the original data were obtained on the morphophysiological characteristics of the predecessors of red blood cells and mature red cells in the peripheral blood of birds in early postnatal ontogenesis using the example of the industrial cross of broiler chickens of neonatal growth and development.

1. Literary sources are analyzed on the issues identified for the purpose of our work.

To date, there are no unified approaches to the classification of cells - the precursors of the erythroid link of vertebrate hemocytopoiesis [29].

In this regard, we presented the classification and morphological and functional characteristics of erythrocyte progenitor cells, according to the most common 
hemocytopoiesis scheme with the designation of erythrocyte precursor cells - erythroblasts: proerythroblasts, basophilic erythroblasts, polychromatophilous erythroblast erythroblasts and peripheral blood erythroblasts postnatal ontogenesis (see Figure 1 and Table 1).

2. The literature sources we analyzed on the morphology of bird erythropoiesis cells gave us reason to consider the information presented today to be insufficient, on the differential diagnosis of progenitor cells in feathered hemocytopoiesis.

In this work, we present differential morphophysiological markers of cell groups - precursors of the development of red blood cells in neonatal ontogenesis of birds.

As a result of the performed staining of peripheral blood smears according to the Pappenheim protocol (histological scheme), we differentiated erythroblasts located at different stages of maturation, as well as erythrocytes of birds.

The following groups of erythroblasts were established: 1 . young forms of basophilic erythroblasts (pro-erythroblasts); 2. Basically erythroblasts; 3. polychromatophilic erythroblasts and 4. hydroxyphilic erythroblasts (see Figure 1 and Table 1).

We have found erythroblasts in the mitotic process. Namely, basophilic erythroblasts in the prophase stage (see Figure 1: 1.4) were found in seven-day-old chickens, basophilic erythroblasts in the early anaphase stage (see Figure 1: 1.5) in blood smears of chickens twenty-three days old, basophilic erythroblasts in the stage of late mitosis anaphase (see figure 1: 1.6) in smears of peripheral blood in chickens of the age of twenty-three days.

3. Based on the literature sources we studied, it was found that the presented microphotographs mainly have low image resolution, often on photographs of erythrocyte precursors, as a result of small magnification, there are no details of the morphological structure by which it is possible to differentiate groups of erythroblasts.

Thanks to our use of a high-quality apochromatic microscopic lens (LOMO, Russia) with a high aperture (1.3) and, accordingly, a large magnification of 90-x, high-quality color micrographs were obtained. This allowed us to carry out, according to morphological criteria, differential diagnosis of erythroblasts that we found in smears of peripheral blood from birds that are in the early stages of growth and development of postnatal ontogenesis.

4. According to the literature we analyzed, it was found that the size of bird erythroblasts is very rare. Information on this issue is rather scattered.

Based on the smears of the peripheral blood of the studied groups of birds that we made, mathematical measurements were performed, namely, the area of the erythroblastic cells of the hematocytopoiesis of birds: the groups of erythroblasts and mature red blood cells was established (see table 1). Statistical processing of mathematically normally distributed arithmetic values of the values of the area of the studied cells was carried out according to the mathematical "Student T - test".

\section{DISCUSSION}

A specific feature of mature bird erythrocytes is a well- formed nucleus in cell cytoplasm (Fig. 1). This morphological feature of cells causes a certain difficulty in identifying the types of formed elements at the stage of their differentiation due to the presence of other, similar nuclear cells in smears of the peripheral blood of birds. This makes morphofunctional diagnostics of peripheral blood cells laborious because smears obtained from chickens in early postnatal ontogenesis contain a large number of immature and even erythropoiesis precursor cells (Fig. 1); under normal conditions, there are no such cells in the blood of mammals. At the same time, there are some specific features in form, micromorphology and histochemistry of cytoplasm and nucleus in the morphophysiology of immature forms of erythrocyte precursor cells that allow their differentiation, both among themselves and from lymphocytes [30], [31] (Fig. 1).

At the same time, cell shape and chromatin structure of the nuclei of mature red blood cells also have differences and depend on the timing of the early postnatal period of ontogenesis in chickens. These features of the morphophysiology of cells in early stages of erythropoiesis are closely connected to age-related changes in glucocorticoid hormones and hormones of the anterior pituitary, such as adrenocorticotropic, somatotropic, and thyrotropic. These hormones, together with erythropoietin, secreted by the reticular base of red bone marrow, and with a number of other factors determine the development and maturation of red blood cells and morphofunctional characteristics of cells in each period of postnatal growth and development of chickens.

According to previous results, shape and structure of erythrocyte nucleus in chickens at the age of 24 hours is similar to that in 42-day-old chickens.

This can be explained by the complex physiological characteristics of the maturation of the broiler bird during these periods of ontogenesis. First of all, by the characteristics of the dynamics of hormone concentrations (somatotropic, adrenocorticotropic, thyrotropic) of the endocrinological status of animals that provide the cash and necessary morphophysiological parameters of red blood cells for the full implementation of their inherent red blood cells functional. These morphological and functional characteristics and parameters of the erythroid link of homeostasis are interconnected with the processes of growth and development, adaptation of the bird at each period of postnatal ontogenesis to vital factors, and the physiological and biochemical characteristics of the constitution of broiler animals with hypertrophied body growth [32].

The nucleus of red blood cells is of basophilic color, of an oval or round oval shape, is formed by a well-structured and intensely colored heterogeneous chromatin which consists of compact lumps of basichromatin, against a lighter colored background of loose oxychromatin. Cells are leaf-like or ellipsoid (Fig. 1). At the age of 7 days, erythrocyte nuclei become of elongated or rod-shaped form. Chromatin of nucleus acquires a well-defined granular structure and is formed by intensely basophilic round-oval nuclei of basichromatin, against the background of a lighter colored, slightly oxyphilic oxychromatin. The shape of cells is 
predominantly oval or ellipsoid. A feature of chick erythrocytes at 23 days of age is more strongly pycnotic nuclei, which is concordant with the data (Fig. 1).

Normally, erythrocyte precursors such as proerythroblasts and erythroblasts circulate in the peripheral blood of chickens (Fig. 1: 1.1 - 1.7; see table). Erythroblasts are functionally active, mitotically proliferating cells that enter bloodstream from red bone marrow pool. Depending on the shape of blast cells, on the color of cytoplasm and chromatin organization in nucleus, the following cells are found in smears of the peripheral blood of birds: pronormocytes $\left(69.60 \pm 4.01 \mu \mathrm{m}^{2}\right.$, $\mathrm{p} \leq 0.05$ ) (Fig. 1: 1.1 - 1.6; see table), basophilic normocytes (65.42 $\left.\pm 2.49 \mu \mathrm{m}^{2}, \quad \mathrm{p} \leq 0.05\right) \quad$ (Fig. 1 : 1.7 ), and polychromatophilic normocytes $\left(71.10 \pm 4.43 \mu \mathrm{m}^{2}\right)$ (Fig. 1: 1.8). Blood picture of chickens reveal young normocytes earlier forms of basophilic normocytes (Fig. 1: 1.1 - 1.3). Cells are round in shape, with active synthetic and pre-mitotic processes in the protoplasm; in this regard, their cytoplasm is rich in ribonucleic acid, therefore, has a significant basophilia, that is, it is colored with ultramarine (Fig. 1: 1.1 - 1.6). Cell nucleus differs from the subsequent ones, i.e. from polychromatophilic erythroblasts; it has an eccentric arrangement and a dark blue color, however, sometimes there are cells with a central arrangement of nucleus and typical cytoplasm pseudopodia (Fig. 1: 1.3).

Typical for birds intravascular erythropoiesis is characterized by the active formation of a cell pool due to the mitotic proliferation of erythroblasts, mainly basophilic ones. Erythroblasts at the prophase stage are found in blood smears, in this phase of mitosis, chromosomes become clearly visible (Fig. 1: 1.4). In the anaphase of mitosis, erythroblast cytoplasm is non-uniformly colored, numerous small vacuoles appear in it giving it a foamy structure; chromosomes are located at the poles of cell (Fig. 1: 1.5). The picture of late anaphase of erythroblast is characterized by two separately located forming nuclei; erythroblast cytoplasm is also vacuolated, therefore it acquires a spongy structure (Fig. 1: 1.6).

Table 1. Morphological parameters of the precursors of red blood cells and mature erythroid cells of chickens Gallus gallus L. of a cross Hubbard ISA F15 (X \pm SEM)

\begin{tabular}{|l|c|}
\hline \multicolumn{1}{|c|}{ Parameter } & $\begin{array}{c}\text { Cell surface area } \\
(\mathrm{S}), \mu \mathrm{m}^{2}\end{array}$ \\
\hline Proerythroblasts & $69.60 \pm 4.01^{*}$ \\
\hline Basophilic erythroblasts & $65.42 \pm 2.49^{*}$ \\
\hline Polychromatophilic erythroblasts & $71.10 \pm 4.43$ \\
\hline Oxyphilic erythroblasts & $68.48 \pm 7.03$ \\
\hline Red blood cells & $73.95 \pm 2.10^{*}$ \\
\hline
\end{tabular}

Notes: $\mathrm{T}-$ test, single sample, ${ }^{*}-\mathrm{p} \leq 0.05$. Checking the normality of the distribution of parameters by the criterion: Kolmogorov Smirnov Lilliefors test for normality and the Shapiro - Wilk test (Shapiro - Wilk's W test), normal probability plot (Normal probability plot: "Normal P-Plot").

The most common form of erythrocyte precursors in the peripheral blood of birds is polychromatophilic erythroblasts
[32]. They contain rounded nuclei with well-structured chromatin. Cell chromatin acquires a different structure and inhomogeneous color: linear (filamentous) represented by oxychromatin and located on the periphery of karyoplasm, and granular, in the form of rounded lumps consisting of basichromatin and located in the central part of karyoplasm (Fig. 1: 1.7).

Erythroblastic precursors are known to have high synthetic activity, in particular, histone proteins and other biopolymers are synthesized in blast blood cells, which provide biological processes for the maturation of erythroblasts into mature red blood cells.

Therefore, due to high synthetic activity, nucleus of a polychromatophilic erythroblast contains a large number of nuclear proteins, histones, therefore it has an intensely basophilic color with a pronounced oxyphilic hue (proteinrelated oxyphilia) (Fig. 1. 1.7).

The optically pronounced oxyphilic hue of polychromatophilic erythroblasts (see Fig. 1.7) is due to the cytochemical features of the perceived dyes when stained according to the Pappenheim protocol (scheme).

Namely, the eosinophil dye (which is part of the Pappenheim histological protocol) is known to have an acidic reaction of the medium, therefore, cytochemically stains nuclear protein (histones) structures (having the main, that is, alkaline reaction of the medium) - the chromatin of a polychromatophilic erythroblast into light oxyphilic, that is, light pink shades (see Fig. 1. 1.7).

In the cytoplasm of polychromatophilic erythroblasts, intense synthesis occurs, primarily of heme and globin in this regard, cytoplasm gradually changes its basophilic color (typical for basophilic erythroblasts) to oxyphilic hue (Fig. 1: 1.7).

Further maturation of polychromatophilic erythroblasts leads to the appearance of polychromatophilic normoblasts in blood picture $\left(71.60 \pm 4.43 \mu \mathrm{m}^{2}\right.$ ) (Fig. 1: 1.8). Processes of conversion of polychromatophilic erythroblasts into normoblasts are characterized by the following changes. 

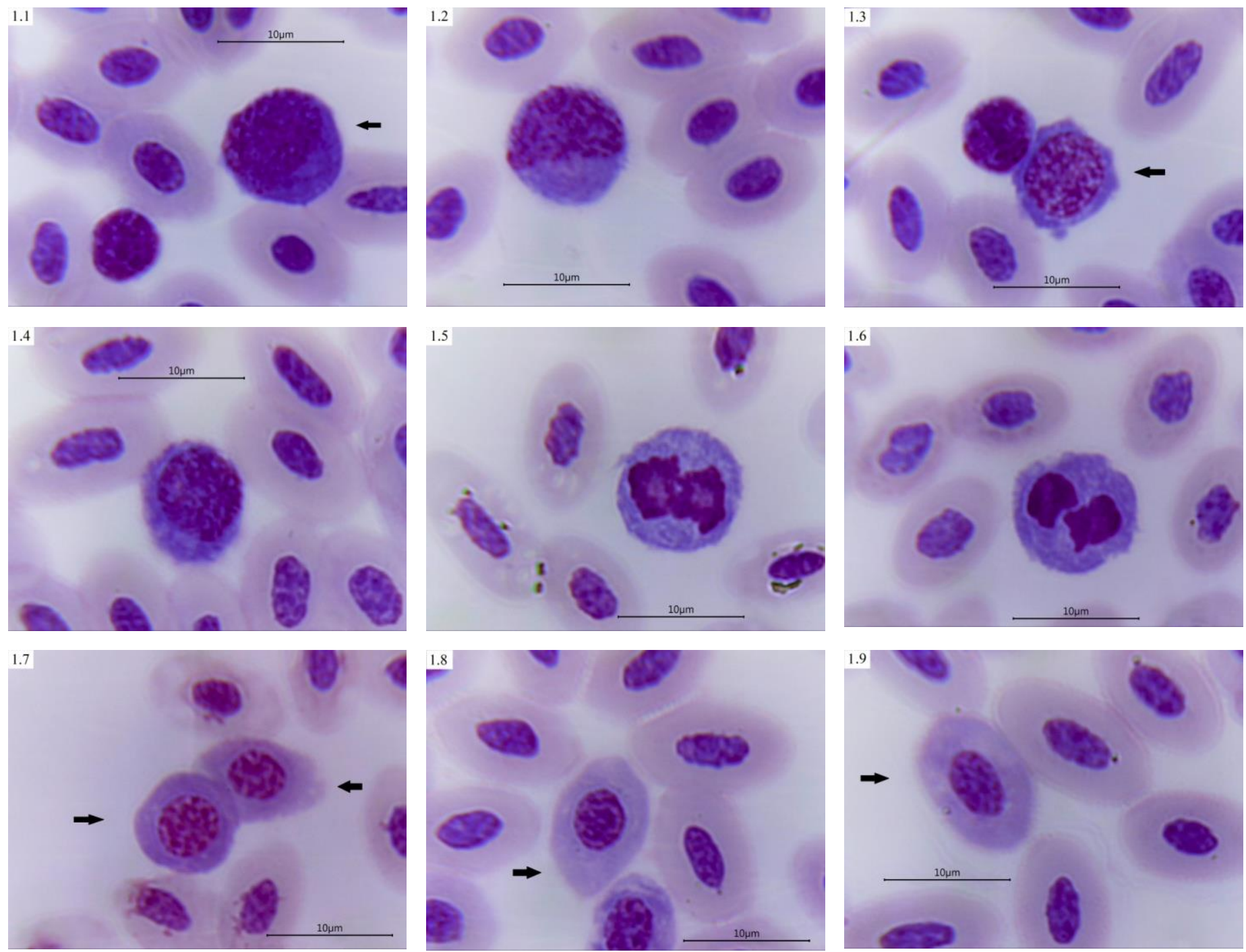

Fig. 1. Peripheral blood of chickens Gallus gallus (L.) (hereinafter, age of birds is specified in brackets). Red blood cell precursors: 1.1, 1.2, 1.3 (7th day) - young forms of basophilic erythroblasts; phases of mitosis of basophilic erythroblasts: 1.4 (7th day) - prophase, 1.5 - early anaphase, and 1.6 - late anaphase: (23rd day); 1.7 (1st day) - polychromatophilic erythroblasts; 1.8 - polychromatophilic erythroblast and 1.9 polychromatophilic erythroblast: (7th day). The arrow indicates a designated object. Scale division line is ten micrometers $(10 \mu \mathrm{m})$.

In cells, there is gradual cessation of mitotic activity and decrease in protein-synthetic, and as a result, a nucleus is forming, with changes in shape and chromatin organization. Nucleus becomes more rounded, chromatin becomes of basophilic color, eosinophilia disappears (Fig. 1: 1.8). Accumulation of hemoglobin in cytoplasm causes gradual decrease in basophilia level in it; a gradient change in cytoplasm color also occurs, from basophilic to weakly basophilic (Fig. 1: 1.8). Transformation of erythroblasts into normoblasts ends with the formation of oval ellipsoid cells (Fig. 1. 1.8). In the subsequent periods of cell development, polychromatophilic normoblasts differentiate into polychromatophilic normocytes $\left(68.48 \pm 7.03 \mu \mathrm{m}^{2}\right)$, including reticulocyte stage. Polychromatophilic normocytes are characterized by typical cytoplasmic polychromasia (Fig. 1: 1.9). So, even greater accumulation of hemoglobin in the cytoplasm of normocytes promotes a gradual transition of the basophilic color of cytoplasm to the oxyphilic one which is typical for mature red blood cells $\left(73.95 \pm 2.10 \mu \mathrm{m}^{2}, \mathrm{p} \leq 0.05\right)$ (Fig. 1: 1.9). The shape of cells and the structure of nucleus and cytoplasm of normocytes become similar to these of mature erythrocytes (Fig. 1: 1.9).

\section{CONCLUSION}

Thus, based on the analysis of high-quality colored microphotographs of peripheral red blood cells of broiler chickens in early postnatal ontogenesis performed by optical microscopy, differential morphophysiological markers of erythrocyte precursors and mature erythroid cells in the early period of bird postnatal ontogenesis were defined and characterized.

In the future, in order to study the characteristics of ontogenetic periods of development and clarify the implementation of physiological, that is, normal adaptations to 
environmental factors in birds, as well as other animals.

The authors plan to continue the study of the morphophysiological characteristics of the cells of the precursors of the erythroid hemocytopoiesis in the peripheral blood, bone marrow hematopoiesis and the dynamics of mature red blood cells in conjunction with the concentration of adrenocorticotropic hormone, corticosterone and cortisol.

\section{RECOMMENDATIONS}

The comprehensive original information obtained by the author on the functional morphology of precursors and mature cells of the erythroid series of birds of early postnatal ontogenesis can serve as a valuable nomenclature classification of the formed elements of the peripheral blood of birds, which are fundamentally different from the blood of mammalian animals.

The differential morphophysiological markers of erythrocyte precursors and mature cells of the erythroid series of the neonatal period of birds, established by the authors, recommended by specialists in veterinary medicine and biological research for physiological and pathophysiological studies, established by the authors

\section{REFERENCES}

[1] T. W. Campbell, B. W. Ritchie, G. J. Harrison, L. R. Harrison. "Hematology", in book: Avian Medicine: Principles and Applications. Lake Worth, Florida: Wingers Publishing, Inc., 1994, pp. 176-198

[2] T. W. Campbell, "Exotic animal hematology and cytology". 4th edition. Ames, Iowa: Wiley-Blackwell. A John Wiley \& Sons, Ltd., Publication, 2015, pp. 403

[3] P. Clark, W. S. J. Boardman, S. R. Raidal. "Atlas of clinical avian hematology", Oxford: Wiley-Blackwell, 2009, pp. 200

[4] Concise Guide to hematology. 2th edition / Edited by $\mathrm{H}$. M. Lazarus, A. H. Schmaier. Cham, Switzerland: Springer, 2019, pp. 542

[5] J. W. Harvey, "Veterinary Hematology: A Diagnostic Guide and Color Atlas", St. Louis, Missouri: Saunders, Elsevier Inc., 2012, pp. 384

[6] L. Palmer. C. Briggs, S. Mcfadden, G. Zini, J. Burthem, G. Rozenberg, M. Proytcheva, S. J. Machin, "ICSH recommendations for the standardization of nomenclature and grading of peripheral blood cell morphological features", International Journal of Laboratory Hematology, Vol. 37 (3), 2015, pp. 287-303

[7] A. V. Hoffbrand, D. R. Higgs, D. M. Keeling, A. B. Mehta Postgraduate haematology, Chichester, West Sussex; Hoboken, New Jersey: John Wiley \& Sons, Ltd, Wiley Blackwell, 2016, pp. 952

[8] K. Kaushansky, M. A. Lichtman, J. T. Prchal, M. Levi, O. W. Press, L. J. Burns, M. A. Caligiuri, "Williams Hematology", 9th Edition. New York, Chicago, San Francisco, Athens, London, Madrid, Mexico City, Milan, New Delhi, Singapore, Sydney, Toronto: McGraw-Hill Education, 2016, pp. 2528
[9] S. Adewoyin, B. Nwogoh, "Peripheral Blood Film - a Review", Annals of Ibadan Postgraduate Medicine, Vol. 12. No. 2, 2014, pp. 71-79.

[10] A. F. Rodak, J. H. Carr, "Clinical Hematology Atlas", 5th Edition. St. Louis, Missouri: Elsevier, Inc., 2017, pp. 296

[11] E. A. Kolesnik, M. A. Derkho, About participation of pituitary-adrenocortical hormones in regulation of blood cellular pool in chicken-broilers, Problems of productive animal biology, No 1, 2018, pp. 64 - 74, doi: 10.25687/1996-6733.prodanimbiol.2018.1.64-74.

[12] M., Derkho, L. Mukhamedyarova, G. Rubjanova, P. Burkov, T. Schnyakina, P. Shcherbakov, T. Shcherbakova, K. Stepanova, G. Kazhibayeva, G., Erythrocytes and their transformations in the organism of cows", International Journal of Veterinary Science, 8(2), 2019, pp. 61-66

[13] A.I. Vorobyov, Guide to hematology, 3rd ed., Moscow: Newdiamed, 2002, pp. 280

[14] M. P. Jones, “Avian Hematology", Clinics in Laboratory Medicine. Vol. 35 (3), 2015, pp. 649-659, doi: 10.1016/j.cll.2015.05.013. PMID: 26297411

[15] A. M. Fudge, "Disorders of avian erythrocytes", Chapter 4, Laboratory medicine: Avian and Exotic Pets, W.B. Saunders, Philadelphia, 2000, pp. 486

[16] E. A. Kolesnik, M. A. Derkho, Characterizing the morphophysiology problems of blood cells of chickens' neonatal ontogenesis. Report I. The features of postembryonic hematopoiesis, differences in approaches and problems of morphofunctional blood analysis (review), Agro-Industrial Complex of Russia, Vol. 26, Issue 4, 2019, pp. 637-643, (In Russian) https://rusapk.sursau.ru/arhive/997/8573/

[17] A. Stier, P. Bize, Q. Schull, J. Zoll, F. Singh, B. Geny, F. Gros, C. Royer, S. Massemin, F. Criscuolo, "Avian erythrocytes have functional mitochondria, opening novel perspectives for birds as animal models in the study of ageing", Frontiers in Zoology, Vol. 10(33), 2013, pp. 1-9, doi:10.1186/1742-9994-10-33. PMID: 23758841.

[18] Aliko, "Comparative blood cell morphology in the peripheral blood films from different vertebrate classess with an adaptation and evolutionary approach", International Conference on Biological \& Environmental Sciences, Tirana, Albania, 2008, pp. 19 - 23, doi:10.13140/2.1.5193.6003.

[19] X. Chen, J. Wang, Q. Wei, M. Hanif, E. Li, S. Zhang, "Morphology and cytochemical patterns of peripheral blood cells in domestic pigeon (Columba livia)", Tissue and Cell, 2019, Vol. 59. pp. 10-17. doi:10.1016/j.tice.2019.05.003.

[20] E. A. Kolesnik, M. A. Derkho, I. A. Lebedeva, Comprehensive morphophysiological description of the immune lysosomal cationic protein of leukocytes in the early ontogeny of broiler chickens, Uchenye Zapiski Kazanskogo Universiteta. Seriya Estestvennye Nauki, Vol. 161, No. 3, 2019, pp. 440-458, (In Russian), doi: 10.26907/2542-064X.2019.3.440-458

[21] E. A. Kolesnik, M. A. Derkho, Characterizing the morphophysiology problems of blood cells of chickens' neonatal ontogenesis. Report II. Characterizing the differential morphophysiological markers of chickens' blood cells, Agro-Industrial Complex of Russia, Vol. 26, 
Issue 4, 2019, pp. 644-652, (In Russian) https://rusapk.sursau.ru/arhive/997/8574/

[22] V. K. Strizhikov, V. V. Sytko, Morphological and histochemical aspects of the adaptation of red blood cells in the blood of pigs in the early phases of the postnatal period of ontogenesis, Bulletin of the Orenburg State Agrarian University, No. 5 (49), 2014, pp. 98-101

[23] P. Clark, S. R. Raidal, "Evaluation of the erythroplastid component of avian blood", Comparative Clinical Pathology, Vol. 23 (4). 2013, pp. 1117-1123, doi:10.1007/s00580-013-1750-4

[24] Griffin Rodgers, P. Young, S. Neal, "The Bethesda handbook of clinical hematology", 4th edition. Philadelphia, Baltimore, New York, London, Buenos Aires, Hong Kong, Sydney, Tokyo: Lippincott Williams \& Wilkins / Wolters Kluwer, 2019, 862 p.

[25] S. S. M. Gallo, N. B. Ederli, M. O. Bôa-Morte, F. C. R. Oliveira, "Hematological, morphological and morphometric characteristics of blood cells from rhea, Rhea Americana (Struthioniformes: Rheidae): a standard for Brazilian birds", Brazilian Journal of Biology. 2015, Vol. 75. № 4. pp. 953-962.

[26] S. Aikins-Wilson, A. R. Barnes, F. Y. Obese, K. A. Agyei-Henaku, The effect of age on haematological studies in ostrich (Struthio camelus), J. Livestock Sci, Vol. 3, 2012, pp. 67-71

[27] A. I. Mustafa, Marwani Asma, K. M. Nasr, N. A. Kano, T. Hadwan, Time Dependent Assessment of Morphological Changes: Leukodepleted Packed Red Blood Cells Stored in SAGM, BioMed Research International, Vol. 1(3), 2016, pp. 4529434 doi:10.1155/2016/4529434 Epub 2016 Jan 21

[28] H. Pendl, Morphological changes in red blood cells of birds and reptiles and their interpretation, Isr. J. Vet. Med, Vol. 61(1), 2006, pp. 1-12

[29] A. A. Khabarova, A. S. Ryzhkova, N. R. Battulin, Chromatin reorganization in the process of erythroid differentiation". Vavilov Journal of Genetics and Breeding, Vol. 23. No. 1, 2019, pp. 95-99, doi: 10.18699 / VJ19.467.

[30] The International Council for standardization in haematology (ICSH), International Council for standardization in haematology: [site], 2019, URL: https://icsh.org/

[31] S. B. McKenzie, J. L. Williams, Clinical Laboratory Hematology, Consulting Editor: K. Landis-Piwowar, Boston, Columbus, Indianapolis, New York, San Francisco, Upper Saddle River, Amsterdam, Cape Town, Dubai, London, Madrid, Milan, Munich, Paris, Montreal, Toronto, Delhi, Mexico City, Sao Paulo, Sydney, Hong Kong, Seoul, Singapore, Taipei, Tokyo: Pearson Education, Inc., 2015, pp.1037

[32] A. C. Guyton, J. E. Hall, Textbook of Medical Physiology", 13th Edition. Edited by J. E. Hall. New York, New York, USA: Elsevier Inc., 2015, pp. 1168, ISBN: 9780323597128

\section{Creative Commons Attribution License 4.0 (Attribution 4.0 International, CC BY 4.0)}

This article is published under the terms of the Creative Commons Attribution License 4.0 https://creativecommons.org/licenses/by/4.0/deed.en_US 